13. Барях А.Б., Андрейко С.С., Федосеев А.К. О механизме локализации очагов газодинамических явлений в почве сильвинитовых пластов // Вестн. ПНИПУ: Геология. Нефтегазовое и горное дело. - 2017. - T. 16, № 3.- С. 247-254. DOI: 10.15593/2224-9923/2017.3.5.

14. Андрейко С.С., Лукьянец Е.В., Литвиновская Н.А., Нестеров Е.А., Бобров Д.А., Поляков А.Л., Лутович Е.А. Параметры профилактической дегазации пород почвы горных выработок при слоевой отработке третьего калийного пласта на рудниках ОАО «Беларуськалий» // Вестн. ПНИПУ: Геология. Нефтегазовое и горное дело. - 2017. - Т. 16, № 3.- С. 280-290. DOI: 10.15593/2224-9923/2017.3.9.

15. Андрейко С.С., Мальцев В.М., Аникин В.В., Жихарев С.Я. Обоснование безопасных параметров буровзрывной отработки сильвинитовых пластов некондиционной мощности совместно с комбайновой выемкой кондиционных пластов на рудниках Верхнекамского месторождения калийно-магниевых солей // Вестн. ПНИПУ: Геология. Нефтегазовое и горное дело. - 2017. - Т. 16, № 4.- С. 357-369. DOI: $10.15593 / 2224-9923 / 2017.4 .7$.

16. Andreyko S.S., Lyalina T.A. Rockburst from floors // Soils and Rocks. - 2019. - V. 42, 1. - P. 77-82. DOI: 10.28927/SR.421077.

17. Андрейко С.С. Современное состояние проблемы газодинамических явлений на действующих и вводимых в эксплуатацию калийных рудниках // Горное эхо. - 2019. - № 2 (75). - С.82-89.

18. Андрейко С.С., Иванов О.В., Нестеров Е.А. Исследование способов предотвращения внезапных отжимов призабойной части соляных пород // Горный журнал. - 2018. - № 6. - С.30-34. DOI: 10.17580/gzh.2018.06.06.

19. Андрейко С.С., Литвиновская Н.А., Сиренко Ю.Г., Чаянов А.Б. Предотвращение газодинамических явлений из почвы горных выработок при различных вариантах столбовой системы разработки на рудниках ОАО «Беларуськалий» // Горн. журн. - 2018. - № 8 . - С. 29-33. DOI: 10.17580/gzh.2018.08.02.

20. Барбиков Д.В., Андрейко С.С., Иванов О.В., Бобров Д.А. Оценка газодинамических характеристик горных пород Краснослободского разлома // Горн. журн. - 2018. - № 8. - С. 38-42. DOI: 10.17580/gzh.2018.08.04

\title{
УСТОЙЧИВОСТЬ ПРОВЕТРИВАНИЯ ШАХТНЫХ СТВОЛОВ В ПЕРИОД ИХ СТРОИТЕЛЬСТВА С ПРИМЕНЕНИЕМ ТЕХНОЛОГИИ ИСКУССТВЕННОГО ЗАМОРАЖИВАНИЯ ПОРОД
}

\author{
М.А. Семин \\ Горный институт УрО РАН, г. Пермь
}

\begin{abstract}
Аннотация: В статье проведено теоретическое исследование конвективных расслоений воздушных потоков при проветривании строящихся вертикальных шахтных стволов в условиях наличия горизонтального градиента температуры. Проведено многопараметрическое численное моделирование нестационарных процессов тепломассопереноса в атмосфере шахтного ствола в двухмерной постановке. Определены критические параметры турбулентного воздушного потока (числа Рэлея), при которых в стволе начинают появляться обратнонаправленные потоки воздуха.

Ключевые слова: шахтный ствол, устойчивость, проветривание, ледопородное ограждение, численное моделирование.
\end{abstract}

\section{Введение}

Согласно действующей на территории России нормативной литературе, строящиеся шахтные стволы необходимо проветривать по всей глубине в течение всего времени их сооружения. Основной схемой проветривания строящихся шахтных стволов, повсеместно применяемой на сегодня, является нагнетательная схема с использованием вентиляционного трубопровода, проложенного от вентиляторной установки на дневной поверхности до тупикового забоя.

В условиях, когда строительство шахтного ствола осуществляется с использованием специального способа искусственного замораживания горных пород [1], температура 
крепи ствола может иметь температуру близкую к $0^{\circ} \mathrm{C}$ или ниже, что является неблагоприятным с точки зрения вентиляции строящегося ствола. Отрицательная температура крепи ствола может приводить к:

- понижению температуры воздуха, обменивающегося теплотой с крепью,

- образованию отрицательного градиента температуры воздуха по высоте ствола, тем самым повышая риск возникновения свободной конвекции в стволе и неуправляемых частично-возвратных течений воздуха.

Появление неуправляемых частично возвратных течений воздуха можно трактовать как переход к неустойчивому проветриванию ствола, так как в этом случае появляется опасность накопления вредных примесей в стволе и локального уменьшения температуры воздуха до значений ниже, чем разрешено нормативными документами $\left(+2^{\circ} \mathrm{C}\right)[2,3]$.

В настоящей статье проводится теоретическое исследование конвективных расслоений воздушных потоков при проветривании вертикальных шахтных стволов в условиях наличия горизонтального градиента температуры, вызванного теплообменом воздуха с крепью ствола.

Настоящая работа является продолжением исследований Б.П. Казакова $[4,5]$ и имеет целью определение критических параметров турбулентного воздушного потока, при которых в вертикальном шахтном стволе начинает развиваться внутристволовая конвекция и появляются обратнонаправленные потоки воздуха. Отличительной особенностью настоящей работы является рассмотрение полностью турбулентного режима течения воздуха. Критерием возникновения конвективного расслоения воздушных потоков и, как следствие, возникновения неустойчивого проветривания горной выработки, является наличие возвратных течений воздуха в поперечном сечении выработки. Основным механизмом формирования возвратных течений воздуха, в отличие от работ Б.П. Казакова, предполагается горизонтальный градиент температуры.

\section{Модель}

Шахтный ствол моделировался в виде вертикального плоского слоя (см. рис. 1). Принималось, что течение воздуха по стволу происходит в направлении «снизу-вверх». Вентиляционный трубопровод в модели не учитывался. Из соображений симметрии рассматривалась только половина слоя, а на центральной оси слоя задавалось граничное условие симметрии. Система координат $O x y$ выбрана таким образом, что ось $x$ направлена горизонтально, а ось $y$ - вертикально. Начало координат соответствует нижнему левому углу слоя.

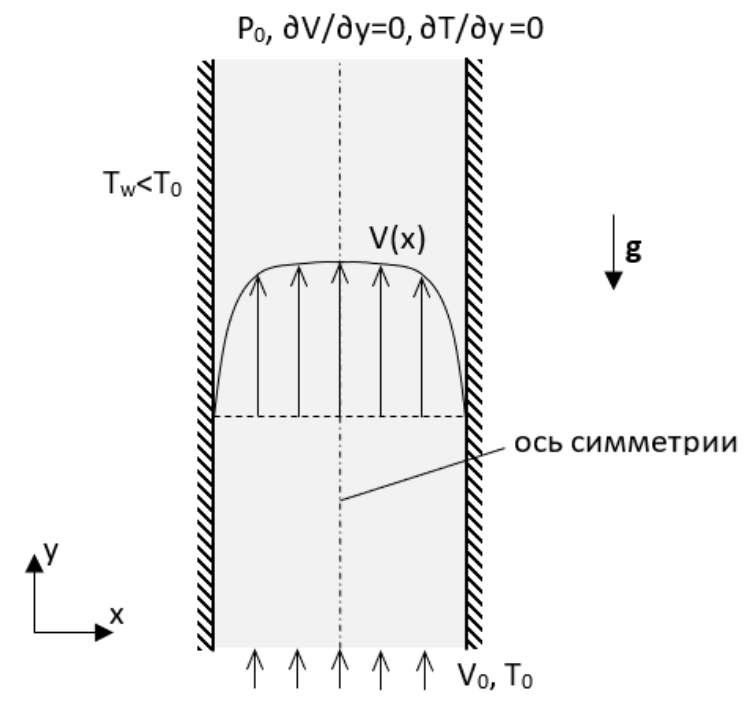

Рис. 1. Геометрия расчетной области 
На входе в расчетную область внизу слоя $(y=0)$ задавались однородно распределенная скорость $V=V_{0}$ и температура воздуха $T=T_{0}$. На выходе из расчетной области вверху слоя $(y=L)$ - нулевое статическое давление и нулевые градиенты основных физических величин. На стенке $(x=0)$ задавалось условие прилипания по скоростям и граничное условие I рода для температуры. Поскольку в данном случае тепло- и массоперенос в пограничном слое моделируется явно, отсутствует необходимость задавать граничное условие третьего рода.

Разработка физической модели тепломассопереноса в атмосфере шахтного ствола и последующее численное моделирование осуществлены в программном комплексе Ansys Fluent. Воздушный поток считался несжимаемым (плотность не зависит от давления), а расчет воздухораспределения осуществлялся с помощью модели турбулентности SST k-omega. Для расчета конвективной стратификации в вертикальном слое плотность задавалась как линейная функция температуры (приближение Буссинеска):

$$
\rho=\rho_{0}+\beta\left(T-T_{0}\right)
$$

где $\rho_{0}$ - отсчетная (референтная) плотность воздуха, кг $/ \mathrm{m}^{3} ; \beta$ - коэффициент объемного расширения воздуха, $1 /{ }^{\circ} \mathrm{C} ; T_{0}$ - отсчетная температура воздуха (равна начальной температуре воздуха, поступающего в расчетную область), ${ }^{\circ} \mathrm{C}$.

Неучет в (1) давления, которое в общем случае существенно влияет на величину плотности воздушного потока, связан с тем, что в горизонтальном сечении ствола изменение давления пренебрежимо мало по сравнению с изменением температуры.

\section{Результаты}

Прежде всего, проведен расчет течения воздуха при нулевом градиенте температур $\left(T_{w}=T_{0}\right)$. На рис. 2 представлены рассчитанные профили безразмерных скорости $V^{\prime}=V / V_{0}$ и эффективной вязкости воздуха $v_{e f f}^{\prime}=v_{e f f} / v_{l}$ в различных поперечных сечениях шахтного ствола на разном удалении $L$ от входа в расчетную область ( $\mathrm{R}$ - радиус ствола). Здесь $\operatorname{Re}=9500$, что соответствует средней скорости воздуха на входе $V_{0}=0,1 \mathrm{~m} / \mathrm{c}$. По оси $x$ отмечена безразмерная радиальная координата $X^{\prime}=x / h$. Ось $x$ выбрана таким образом, что ее начало находится на стенке ствола. Профили безразмерной турбулентной вязкости представлены в логарифмических осях, а профили безразмерной скорости - в обычных.

Изменение профиля скорости вдоль продольной координаты (см. рис. 2а) обусловлено постепенным развитием возмущений в пограничном слое по мере продвижения потока от входа в расчетную область вверх. При $L>60 R$ профиль скорости изменяется несущественно, при этом профиль безразмерной эффективной вязкости в ядре потока меняется по-прежнему заметно (см. рис. 2б). Однако получаемое поле скоростей определяется преимущественно характером изменения эффективной вязкости вблизи стенки ствола $\left(X^{\prime}<0,05\right)$, т.е. на том отрезке, где эффективная вязкость изменяется от значения, равного ламинарной вязкости, до значения порядка вязкости в турбулентном ядре потока.

Далее проведена серия расчетов течения воздуха при отличном от нуля градиенте температур $A=\left(T_{0}-T_{w}\right) / h>0$. На рис. 3 представлены рассчитанные профили безразмерных скорости $V^{\prime}=V / V_{0}$ и эффективной вязкости воздуха $v_{e f f}^{\prime}=v_{e f f} / v_{l}$ в различных поперечных сечениях шахтного ствола на разном удалении $L$ от входа в расчетную область при $T_{0}=5^{\circ} \mathrm{C}$ и $T_{w}=0^{\circ} \mathrm{C}\left(A=1,25^{\circ} \mathrm{C}\right)$. 
a)

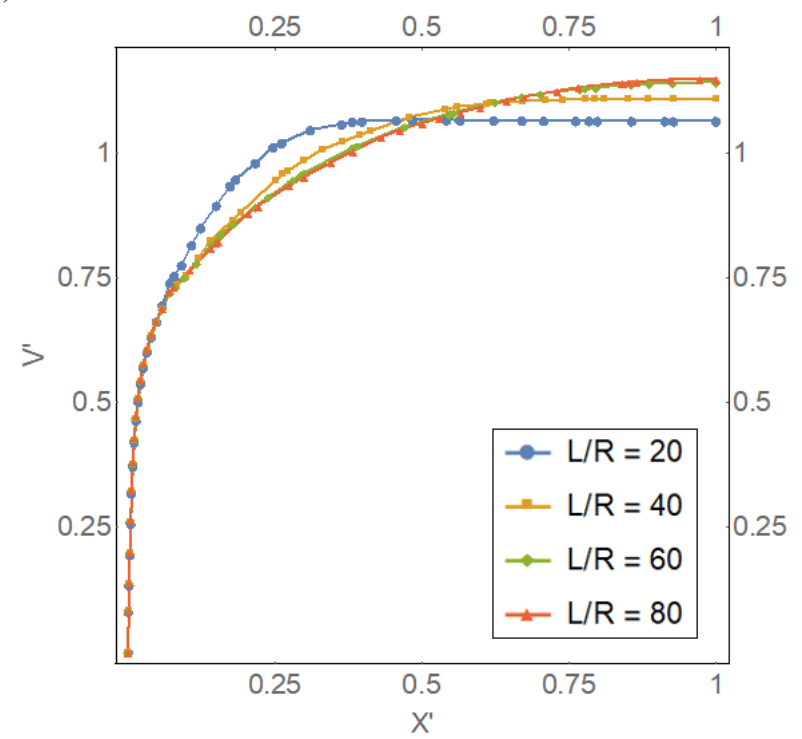

б)

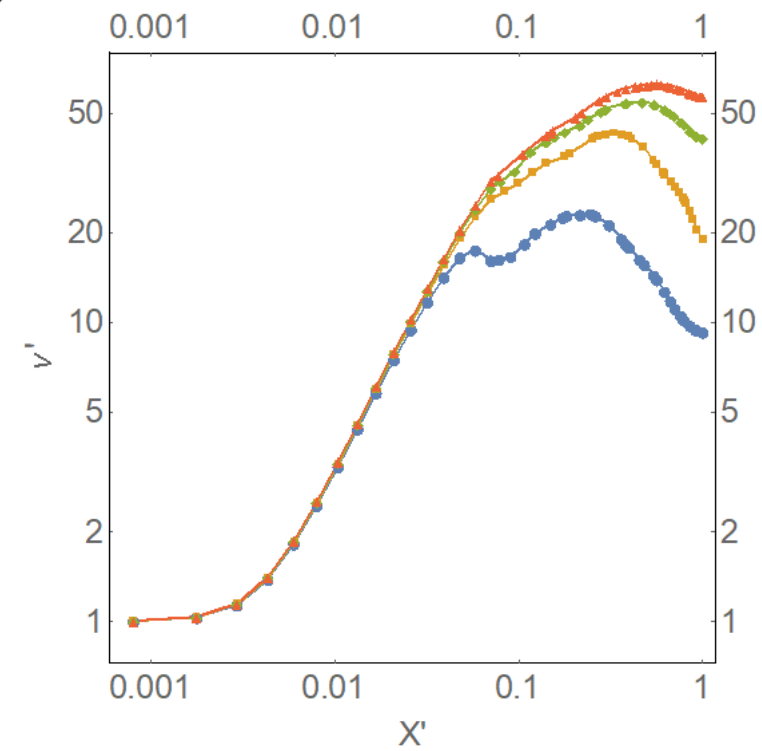

Рис. 2. Профили безразмерных скорости воздуха (а) и эффективной вязкости воздуха (б) в различных поперечных сечениях шахтного ствола при $R e=9500$

a)

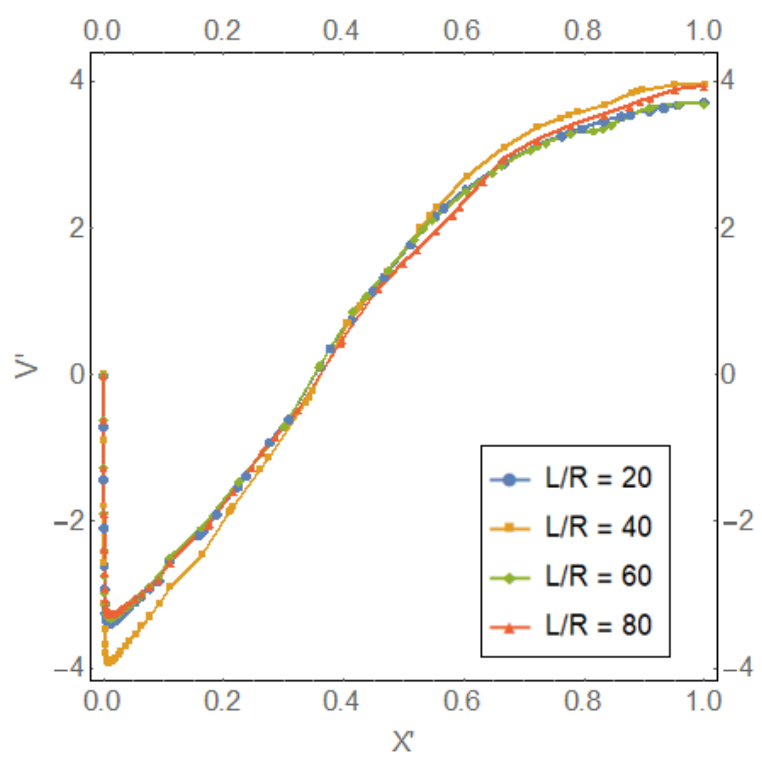

б)

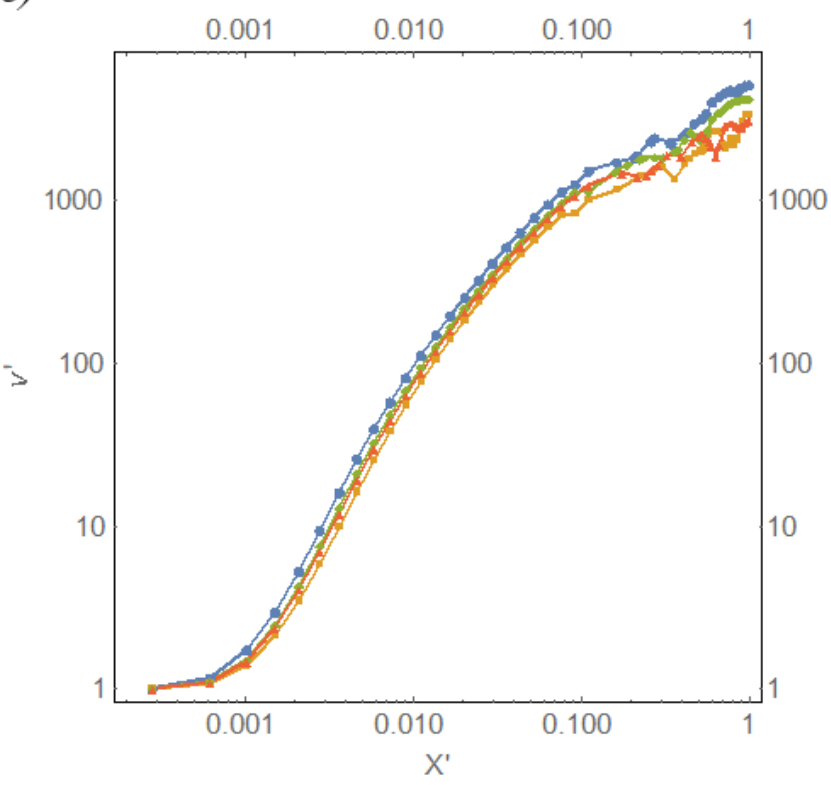

Рис. 3. Профили безразмерных скорости воздуха (а) и эффективной вязкости воздуха (б) в различных поперечных сечениях шахтного ствола при $\mathrm{Re}=9500$ и температурном градиенте $\mathrm{A}=1,25^{\circ} \mathrm{C} / \mathrm{M}$

Из рис. За видно, что профиль скорости воздуха существенно изменился - в области вблизи стенки $\left(\mathrm{X}^{\prime}<0,4\right)$ появилось возвратное течение воздуха по всей длине шахтного ствола, что говорит о формировании одного или нескольких конвективных вихрей в стволе. Скорость воздуха также существенно возросла по магнитуде (с $1,27 V_{0}$ до $\left.4 V_{0}\right)$.

Профиль эффективной вязкости (см. рис. 3б) сильно отличается от случая с нулевым температурным градиентом - ее величина возросла на два порядка в турбулентном ядре потока. Возрастание эффективной вязкости связано с увеличением средней скорости воздуха в стволе за счет наложения на поступательное движение воздуха дополнительной компоненты скорости, связанной с циркуляцией воздуха в конвективных ячейках в стволе. 


\section{Критическое число Рэлея}

Мерой интенсивности конвективного расслоения в стволе могут служить максимальная и минимальная скорости воздушного потока. При постепенном увеличении величины температурного градиента от нуля и выше максимальная скорость воздушного потока в сечении должна увеличиваться, что можно трактовать как нарушение формы поперечного профиля скорости в стволе. При этом минимальная скорость воздушного потока, изначально равная нулю, в определенный момент должна начать уменьшаться, что будет указывать на возникновение возвратных течений воздуха в сечении ствола. Минимальное значение температурного градиента, при котором минимальная скорость воздушного потока становится отрицательной, следует расценивать как критическое, при котором происходит нарушение устойчивого проветривания.

На рис. 4 представлены зависимости максимальной и минимальной скоростей воздушного потока в стволе от величины числа Рэлея - безразмерного температурного градиента:

$$
\mathrm{Ra}_{\kappa p}=\frac{g \boldsymbol{\beta} \boldsymbol{A} \boldsymbol{h}^{\mathbf{4}}}{\boldsymbol{v}_{l} \chi_{l}} .
$$

Здесь $g$ - ускорение свободного падения, м/ $\mathrm{c}^{2} ; \beta$ - коэффициент объемного расширения воздуха, $1 /{ }^{\circ} \mathrm{C} ; A-$ продольный температурный градиент, ${ }^{\circ} \mathrm{C} / \mathrm{m} ; h-$ характерный размер (радиус) ствола, м; $v_{l}$ - ламинарная кинематическая вязкость воздуха, $\mathrm{m}^{2} / \mathrm{c} ; \chi_{l}-$ ламинарная температуропроводность воздуха, $\mathrm{m}^{2} / \mathrm{c}$.

Значения минимальной скорости на рис. 4 приведены по модулю для того, чтобы отобразить обе зависимости в логарифмических осях.

Рассчитанное критическое значение безразмерного температурного градиента $\mathrm{Ra}_{\mathrm{kp}}$, при котором минимальная скорость воздушного потока становится отрицательной, равно приблизительно $7,4 \cdot 10^{9}$. При этом значение Ra, при котором начинается существенное (10\%) изменение поперечного профиля скорости воздушного потока, ниже $\mathrm{Ra}_{\text {кр }}$ и составляет приблизительно $4,3 \cdot 10^{9}$.

Следует отметить, что полученные оценки чисел $\mathrm{Ra}_{\text {кр }}$ и $\mathrm{Ra}_{\text {вп }}$ зависят от скорости воздушного потока, задаваемой на входе в расчетную область. Кривые, представленные на рис. 4, соответствуют скорости воздушного потока 0,1 м/с на входе в расчетную область, или числу $R e$, равному $\approx 9500$.

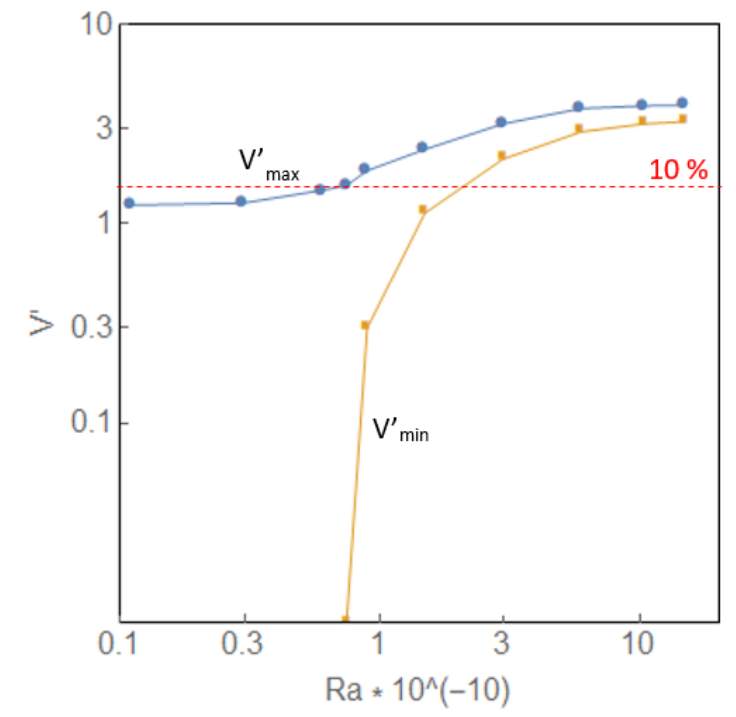

Рис. 4. Зависимости максимальной и минимальной скоростей воздушного потока в поперечном сечении ствола $\mathrm{L}=80 \mathrm{R}$ от величины безразмерного температурного градиента $\mathrm{Ra}$ (принято, что $\mathrm{Re}=9500$ ) 
В работе также исследованы значения числа $\mathrm{Ra}_{\text {кр }}$ при других значениях числа $\mathrm{Re}=\mathrm{hV} \mathrm{V}_{0} / v_{\mathrm{l}}$. В результате получена следующая аппроксимационная функция для определения величины критического числа Рэлея:

$$
\mathrm{Ra}_{c r}^{*}=\frac{\mathrm{Ra}_{c r}}{10^{10}}=0,19 \operatorname{Re}^{1 / 4}-1,19 .
$$

Если теперь перейти в (3) от безразмерных физических величин к размерным и выразить скорость воздуха в стволе, мы получим:

$$
V_{\text {min }}=\frac{v_{l}}{R}\left(\frac{g \beta \Delta T R^{3}}{0,19 v_{l} \chi_{l} \cdot 10^{10}}+6,26\right)^{4}
$$

Скорость $\mathrm{V}_{\min }$ можно интерпретировать как минимально допустимую скорость воздуха в шахтных стволах, при которой исключаются возвратные потоки воздуха и неконтролируемая рециркуляция воздуха. Эта функция может использоваться при проектировании систем вентиляции для сконструированных шахт и шахт в случае низких скоростей воздуха и значительного перепада температур $\Delta \mathrm{T}$ между воздухом и окружающей массой горных пород.

\title{
Исследование выполнено при финансовой поддержке Программы ФНИ, проект № 0422-2019-0145-С-01 (регистрационный номер темы НИОКТР: AAAA-A18-118040690029-2).
}

\section{БИБЛИОГРАФИЧЕСКИЙ СПИСОК}

1. Левин Л.Ю., Семин М.А., Зайцев А.В. Решение обратной задачи Стефана при анализе замораживания грунтовых вод в породном массиве // Инженерно-физический журнал. - 2018. - Т. 91, №3. - С. 655-663.

2. Левин Л.Ю. Семин М.А., Клюкин Ю.А., Накаряков Е.В. Исследование аэро- и термодинамических процессов, протекающих на начальном этапе организации сквозного проветривания рудника // Вестн. ПНИПУ: Геология. Нефтегазовое и горное дело. - 2016. - Т. 15, № 21.- С. 367-377. DOI: 10.15593/2224-9923/2016.21.9.

3. Левин Л.Ю., Семин М.А., Клюкин Ю.А. Экспериментальное исследование изменения воздухораспределения на калийных рудниках при реверсировании главной вентиляторной установки // Вестн. ПНИПУ: Геология. Нефтегазовое и горное дело. - 2015. - Т. 14, № 17. - C.89-97. DOI: 10.15593/22249923/2015.17.10.

4. Казаков Б.П., Шалимов А.В., Сёмин М.А., Гришин Е.Л., Трушкова Н.А. Конвективная стратификация воздушных потоков по сечению горных выработок, ее роль в формировании пожарных тепловых депрессий и влияние на устойчивость проветривания // Горный журнал. - 2014. - №12. - С. 105-109.

5. Казаков Б.П., Шалимов А.В. Устойчивость конвективного проветривания рудника после отключения вентилятора // // Физико-технические проблемы разработки полезных ископаемых. - 2019. - № 4. C. 122-130. DOI: 10.15372/FTPRPI20190413.

УДК 629.039 .58

DOI:10.7242/echo.2020.2.24

\section{УСТОЙЧИВОСТЬ АДВЕКТИВНОГО ДВИЖЕНИЯ ВОЗДУХА \\ В ГОРИЗОНТАЛЬНЫХ ГОРНЫХ ВЫРАБОТКАХ С ИСТОЧНИКАМИ ВЫДЕЛЕНИЯ ТЕПЛА}

\author{
А.В. Шалимов \\ Горный институт УрО РАН, г. Пермь
}

Аннотация: Представлены результаты аналитических исследований развития пожара в горизонтальной горной выработке после отключения источника тяги. Показано, что однозначный прогноз движения воздуха в данном случае возможен только на основе теории устойчивости конвективных течений. В квазистационарной постановке проведено математическое моделирование ад- 